Костюнин А. Е., Овчаренко Е.А., Барбараш О. $\Lambda$.

ФГБНУ «Научно-исследовательский институт комплексных проблем

сердечно-сосудистых заболеваний», 650002, Кемерово, Сосновый бульвар, 6

\title{
РЕНИН-АНГИОТЕНЗИН-ААЬАОСТЕРОНОВАЯ СИСТЕМА
}

\section{КАК ПОТЕНЦИААЬНАЯ МИШЕНЬ ААЯ ТЕРАПИИ ПАЦИЕНТОВ

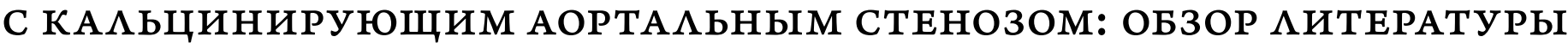

КАючевые слова: аортацьный стеноз; ренин-ангиотензин-ацьдостероновая система;

камьцификация; патофизиология; консервативная терапия; ингибиторы АПФ

Ссылка дяя циитирования: Костюнин А. Е., Овчаренко Е. А., Барбараи О. А.

Ренин-ангиотензин-альдостероновая система как потенциальная мичень дяя терапии пациентов

с кальцинирующим аортальным стенозом: обзор литературы. Кардиология. 2019;59(11S):4-17

Резюме

Кальцинирующий аортальный стеноз (КАС) преАставмяет собой серьезную социально-экономическую проблему в развитых странах, поскольку явцяется наиболее частым показанием к протезированию аортального клапана. В настоящее время не существует методов неинвазивного мечения этого заболевания. Тем не менее, предполагается, что эффективная фармакотерапия КАС может быть разработана на основе модумяторов ренин-ангиотензин-альдостероновой системы (РААС), вовлеченной в патогенез этого заболевания. Целью настоящего обзора является обобщение и анализ современной информации о роли РААС в патофизиологии КАС, рассмотрение последних Аанных по эффективности ингибиторов РААС в мечении Аанного порока.

Kostyunin A.E., Ovcharenko E. A., Barbarash O.L.

Research Institute for Complex Issues of Cardiovascular Diseases, Sosnovy Bulvar 6, Kemerovo, 650002

\section{THE RENIN-ANGIOTENSIN-ALDOSTERONE SYSTEM}

\section{AT A POTENTIAL TARGET FOR THERAPY IN PATIENTS WITH CALCIFIC AORTIC STENOSIS: A LITERATURE REVIEW}

Keywords: aortic stenosis; renin-angiotensin-aldosterone system; calcification; pathophysiology; conservative treatment; ACE inhibitors For citation: Kostyunin A. E., Ovcharenko E. A., Barbarash O. L. The renin-angiotensin-aldosterone system at a potential target for therapy in patients with calcific aortic stenosis: a literature review. Kardiologiia. 2019;59(11S):4-17

Summary

Calcific aortic valve stenosis (CAVS) is a serious socio-economic problem in developed countries because this disease is the most common indication for aortic valve replacement. Currently, there are no methods for non-invasive treatment of CAVS. Nevertheless, it is assumed that effective drug therapy for CAVS can be developed on the basis of modulators of the renin-angiotensin-aldosterone system (RAAS), which is involved in the pathogenesis of this disease. The purpose of this paper is to compile and analyze current information on the role of RAAS in the CAVS pathophysiology. Recent data on the effectiveness of RAAS inhibition are reviewed.

Information about the corresponding author: Kostyunin A. E., e-mail: rhabdophis_tigrina@mail.ru

\section{Введение}

Кальцинирующий аортальный стеноз (КАС) является наиболее распространенной формой аортального стеноза во всем мире, особенно часто Аанная патология встречается среди жителей развитых стран [1]. Этот порок поражает миц прекмонного возраста и обнаруживается у 2-7\% пациентов старше 65 мет [2]. В связи со сложившейся тенденцией увеличения продолжительности жизни и демографического старения населения развитых стран в ближайшие десятилетия прогнозируют существенный рост числа больных
КАС [3-6]. Поскольку разработка медикаментозной терапии КАС Ао сих пор не увенчалась успехом [7, 8], еАинственным способом коррекции этого порока явмяется хирургическое протезирование пораженного нативного клапана [9-11]. Впрочем, в настоящее время активно ведутся исследования, нацеменные на созАание эффективных методов неинвазивного мечения КАС. В качестве возможных вариантов рассматривается применение статинов, иАПФ и блокаторов рецепторов ангиотензина (БРА), бисфосфонатов и ряда Аругих препаратов [7]. 
Важно отметить, что за последние 20 мет произошел прорыв в понимании патофизиологии КАС [1]. Если раньше Аанный порок считался пассивным дегенеративным заболеванием, то сегодня известно, что патогенез КАС сложен и отчасти напоминает атеросклеротическое поражение сосудов, разделяя с ним общие ФР и гистопатологические события, такие как эндотелиальная Аисфункция, воспаление, фиброз и кальцификация [12]. К настоящему времени уже идентифицированы основные молекулярные пути и кметочные агенты, способствующие развитию и прогрессированию КАС [1], намечены главные терапевтические мишени дмя разработки консервативного мечения [7]. Среди наиболее перспективных мишеней Амя фармакотерапии КАС выдемяется РАAС.

Ренин-ангиотензин-альдостероновая система была открыта более века назад. Она представмяет собой одну из ключевых гормональных систем организма, которая подАерживает почечный и сердечно-сосудистый гомеостаз посреАством регумяции просвета сосудов и водно-электролитного баланса [13]. В посмедние годы взгляды на РААС как на классическую вазорегулирующую систему в корне изменились. Многочисленные экспериментальные работы показывают, что отдельные ее компоненты проявмяют цитокиноподобные свойства и участвуют в таких процессах, как пролиферация и дифференцировка кметок [14-16], синтез внеклеточного матрикса и протеолитических ферментов [16-18], генерация кислородных радикалов [19-21], выброс цитокинов, хемокинов и белков острой фазы воспаления [22-24], экспрессия момекул кметочной аАгезии [20, 25] и т. А. Кроме того, сегоАня Аисрегуляция РААС ассоциируется с различными патологиями. Известно, что она задействована в патогенезе таких заболеваний, как артериальная гипертензия (АГ) [26], атероскмероз [27, 28], рак $[29,30]$, СА [31,32] и ХПН [33], причем некоторые из этих состояний тесно связаны с процессами, кежащими в основе патофизиологии КАС. Более того, современные Аанные свидетельствуют о том, что активация РААС играет значимую роль в самой клапанной кальцификации [1].

Bсе вышеизможенное позволяет предполагать, что регумяция свойственных КАС патологических процессов может хотя бы отчасти осуществляться через модумяцию функций РААС. Это ставит вопрос о потенциальной эффективности фармакотерапии, основанной на использовании иАПФ и БРА Аля замеАления склерозирования и кальцификации аортального кмапана (АК). Целью настоящего обзора явмяется обобщение и анаАиз современной информации, касающейся роли РААС в этиопатогенезе КАС, рассмотрение послеАних Аанных по эффективности ингибиторов РААС в мечении КАС.
Основные компоненты РАAC

и их потенциальная роль в патофизиомогии КАС

\section{Ангиотензин II, его рецепторы \\ и физиологические функиии}

Ангиотензин (АТ) II явмяется центральным компонентом классической РААС и ее главным биоактивным эффектором. Функциональные эффекты АТ II опосреАуются рецепторами АТ II типа 1 и 2 (АТ1-Р и АТ2-P), относящимися $\mathrm{K}$ семиспиральным или G-протеинсопряженным рецепторам [34]. Они имеют гомологичную структуру, но размичаются функционально [35]. КАассические эффекты АТ II, включающие индукцию вазоконстрикции, пролиферации, воспаления, фиброза и гипертрофии зависят от взаимодействия AT II с AT1-P $[34,36]$. В свою очередь вазодилатация, антивоспалительные, антифиброгенные и антигипертрофические эффекты АТ II опосредуются через АТ2-P [36]. Важно отметить, что зАоровые аортальные киапаны, по-видимому, защищены от небцагоприятного воздействия AT II, что связано с особенностями экспрессии АТ1-Р и АТ2-Р. Так, группой финских ученых показано более чем пятикратное увеличение уровней AT1-Р в стенозированных клапанах по сравнению с неизмененными, тогАа как уровни АТ2-Р оказались ниже предела обнаружения и в пораженных, и в зАоровых клапанах [37]. В Аругом исследовании показано, что уровни экспрессии матричной рибонукмеиновой кислоты (мРНК) АТ1-Р могут существенно не изменяться по мере развития склеротического поражения и камьцификации АК, в то время как уровни мРНК АТ2-Р резко снижаются при прогрессировании болезни [38]. Наконец, еще одно исследование демонстрирует, что экспрессия АТ1-Р обнаруживается мишь в $18 \%$ неизмененных, но в 75\% стенозированных аортальных клапанов [39]. ОАнако необходимо учитывать, что эти Аанные могут и не отражать истинных закономерностей, поскольку получены на очень ограниченной выборке [39]. Также стоит упомянуть, что экспрессия АТ 1-Р не типична аля вальвулярных фибробластов здоровых кмапанов, но отмечается при их активации и переходе к миофибробластическому фенотипу, наблюдаемому при развитии свойственных КАС патологических изменений $[37,39]$.

Таким образом, в неизмененных АК наблюдается низкая экспрессия АТ1-Р, что ограничивает возможности АТ II инициировать воспалительные и фиброзные реакции. Более высокие уровни экспрессии АТ2-Р, вероятно, также защищают зАоровый клапан от вредного воздействия AT II. По мере прогрессирования КАС баманс межАУ AT1-Р и АТ2-Р постепенно нарушается: наблюдается снижение экспрессии АТ2-Р, тогАа как экспрессия АТ1-Р либо увеличивается, либо не изменяется. Так или иначе, равновесие смещается в сторону АТ 1-Р, что преАраспола- 
гает к активации РААС и преоблаАанию воспалительных и фиброгенных сигналов.

Связывание AT II с AT 1-Р приводит к трансаукции сигнала внутрь клетки через активацию зависимых и независимых от G-белков сигнальных путей, что в свою очередь активирует множество сигнальных молекул и транскрипционных факторов, вкмючая ERK1/2, JNK, p38 MAPK, JAK/STAT, NF-кB и Ар. [34]. Эти сигнамы инАуцируют увеличение экспрессии разнообразных цитокинов, хемокинов и факторов роста, включая интерлейкины $1,6,8$, фактор некроза опухоли $\alpha$, трансформирующий фактор роста $\beta 1$, моноцитарный хемотаксический фактор-1, которые опосредуют размичные функциональные эффекты AT II, такие как усимение синтеза белков матрикса и матрикс-деградирующих ферментов, активацию процессов пролиферации, миграции, Аифференцировки и гибели клеток $[34,40]$.

Особое внимание обращает на себя тесная связь АТ II и окислительного стресса [41]. Известно, что АТ II активирует НААФН-оксидазу и, следовательно, усимивает окислительный стресс за счет увеличения концентраций кислородных раАикалов, таких как перекись водорода и супероксиА-анион $[34,41]$. В свою очереАь, повышение окислительного стресса ассоциируется с размичными СС3 [34, 41], вкмючая КАС [42-44]. Перепроизводство кислородных соеАинений способствует снижению продукции оксида азота эндотелием и его Аеактивации, внеклеточному окислению мипопротеинов, активации протеолитических ферментов и многочисленных сигнальных молекул и транскрипционных факторов, включая ERK5, JNK, p38 MAPK, MSx2, Runx2, JAK/STAT и NF-кB [34, 41, 44]. Помимо этого, радикалы кислорода провоцируют перекисное окисмение мипиАов, повреждение белков и молекул АНК, вызывая гибель клеток через апоптоз или некроптоз $[45,46]$. Таким образом, способность АТ II индуцировать производство кислородных раАикалов и, тем самым, усугублять окислитемьный стресс является, пожалуй, наиболее значимым его свойством.

Bce вышеперечисленные функциональные эффекты AT II могут иметь важное значение Аля процессов фиброзно-склеротического ремоделирования и кальцификации АК. Участие AT II в развитии фиброза и камьцификации клапанов подтвержАается рядом экспериментальных работ in vitro и in vivo. Например, обработка AT II культивируемых вальвумярных миофибробластов свиньи приводила к их активации и усилению экспрессии a-гладкомышечного актина [47] Кроме того, Аобавмение в кумьтуру AT II вызывамо повышение экспрессии мРНК костного морфогенетического белка-2 и щелочной фосфатазы, усименную секрецию морфогена Wnt3a, активацию сигнального каскада Wnt и переход части миофибро- бластов к остеогенному фенотипу [47]. Стоит отметить, что опосреАованная АТ II остеогенная Аифференцировка клапанных клеток может происходить и по пути активации сигнала RANKL ( ииганда рецептора-активатора ядерного фактора каппа- $\beta$ ), как это показано на примере культур гладкомышечных киеток сосудов человека и сосуАистой камьцификации у мышей [24]. В свою очереАь исследование на АроЕ-нокаутных мышах демонстрирует, что введение высоких доз АТ II вызывает утолщение створок клапанов, сопровожАаемое поврежАением энАотелиальных клеток и увеличением количества вальвулярных миофибробластов, причем эти изменения не связаны с инауцируемым АТ II повышением АА [48]. В Аругом исслеАовании показано, что ввеАение гиперхолестеринемическим кроликам блокаторов AT1-P предотвращает утолщение АК, которое развивается у них на богатой XС Аиете [49]. При этом в АК подопытных животных отмечено снижение экспрессии мРНК Runx2 и секреции остеопонтина, уменьшение количества миофибробластов, а также малая интенсивность мипидной и мейкоцитарной инфильтрации по сравнению с кроликами в положительном контроле [49]. Эти Аанные также предполагают центральную роль АТ II в наблюдаемых у кроликов патологических процессах.

Как уже отмечалось ранее, хроническая гиперактивация РААС, сопровожАающаяся повышением уровня AT II в плазме и тканях, ведет к развитию ряда серАечно-сосуаистых и почечных заболеваний. Наличие таких патологий, как АГ и почечная неАостаточность, не только связано с более неблагоприятным кминическим прогнозом у больных КАС $[50,51]$, но и может становиться причиной появмения ими ускорения прогрессии этой бомезни $[52,53]$. Например, АГ часто сопутствует КАС, а ее основное вмияние на прогрессирование кмапанной камьцификации объясняется повышением механической нагрузки на створки клапана вследствие воздействия на них аномальной гемодинамики [54]. Кроме того, считается, что АГ может выступать в качестве триггера КАС, способствуя поврежАению энАотелиального слоя створок [55]. В свою очереАь ХПН Аополнительно ускоряет и усимивает процессы камьцификации АК, поскомьку провоцирует нарушения камьций-фосфорного обмена и метабомизма ингибиторов минерахизации, таких как фетуина-А и матриксного Gla-белка [56]. Поскольку AT II задействован в патофизиологии этих заболеваний, можно говорить, что РААС оказывает не только прямое вАияние на прогрессию КАС, провоцируя усиление воспалительных, фиброгенных и остеогенных реакций непосредственно в клапане, но и способствует развитию порока через изменение гемодинамических и биохимических параметров внутренней среАы организма. 


\section{АТ II в пораженных клапанах}

Ангиотензин II образуется в ходе каскада реакций, включающих активацию ренина, расщепление ангиотензиногена до АT I и переход AT I в AT II. Ренин преАставмяет собой фермент из класса гидролаз, он образуется из проренина, синтезируемого в почках [13]. Активация проренина может происходить Авумя способами, включающими необратимое протеолитическое отщепление 43-аминокислотного просегмента и обратимое изменение конформации при связывании с (про) рениновым рецептором (ПРР), в ходе которого просегмент выхоАит из каталитического центра фермента, но не отАеляется от него [34]. ПреАположительно, опосреАуемый ПРР непротеолитический механизм образования ренина может мокацьно активировать РААС в тканях пораженных клапанов [35]. ПРР способен связываться и с проренином, и с ренином $[34,35]$, причем это взаимодействие увеличивает ферментативную активность послеАнего в 4-5 раз [34]. Поскольку оАной из основных функций ренина является гиАролиз продуцируемого печенью ангиотензиногена до AT I, активация этого фермента в клапане будет способствовать мокальному накоплению АТ I. В свою очереАь АT I, как считается, не облаАает биологической активностью и служит субстратом Аля АПФ, химазы или катепсина $\mathrm{G}$, поА Аействием которых он превращается в АТ II [35]. Существует и амьтернативный путь получения АТ II из неАавно открытых промежуточных пептидов АТ (1-12) и АТ (1-25), причем ренин и АПФ не участвуют в этом каскаде. АТ (1-12) и AT (1-25), вероятно, образуются из ангиотензиногена поА Аействием неопознанных ферментов и Аахее преобразуются химазой в АT II [57-59]. Важно отметить, что опосредованный химазой перехоА АТ (1-12) в АT II, по-видимому, явмяется основным путем образования АТ II в тканях сердца $[60,61]$.

Примечательно, что в стенозированных АК наблюАается повышенное содержание основных компонентов PAAC и в частности всех трех AT II-образующих ферментов $[37,39,62]$. Накопление послеАних тесно связано с мипиАной и мейкоцитарной инфильтрацией, сопровожАающих воспалительные процессы на ранних стадиях КАС. Показано, что в тканях пораженных клапанов формируются плотные клеточные инфильтраты, состоящие преимущественно из макрофагов, Т-лимфоцитов и тучных клеток [63-65]. При этом макрофаги продуцируют АПФ [39], тогАа как тучные клетки высвобожАают химазу и катепсин $\mathrm{G}[37,62]$. Еще одним важнейшим источником АПФ в тканях клапанов, по-видимому, становятся циркулирующие в крови мипопротеины, к которым прикрепляется фермент. Аавно известно, что мипиАная инфимьтрация имеет место у бомьных КАС $[66,67]$

\section{Для mex, кmo любит жизнь всем сердчем!}

\section{Эспиро снижает смертность у пациентов с сердечной недостаточностью и перенесиих инфаркт миокарда}

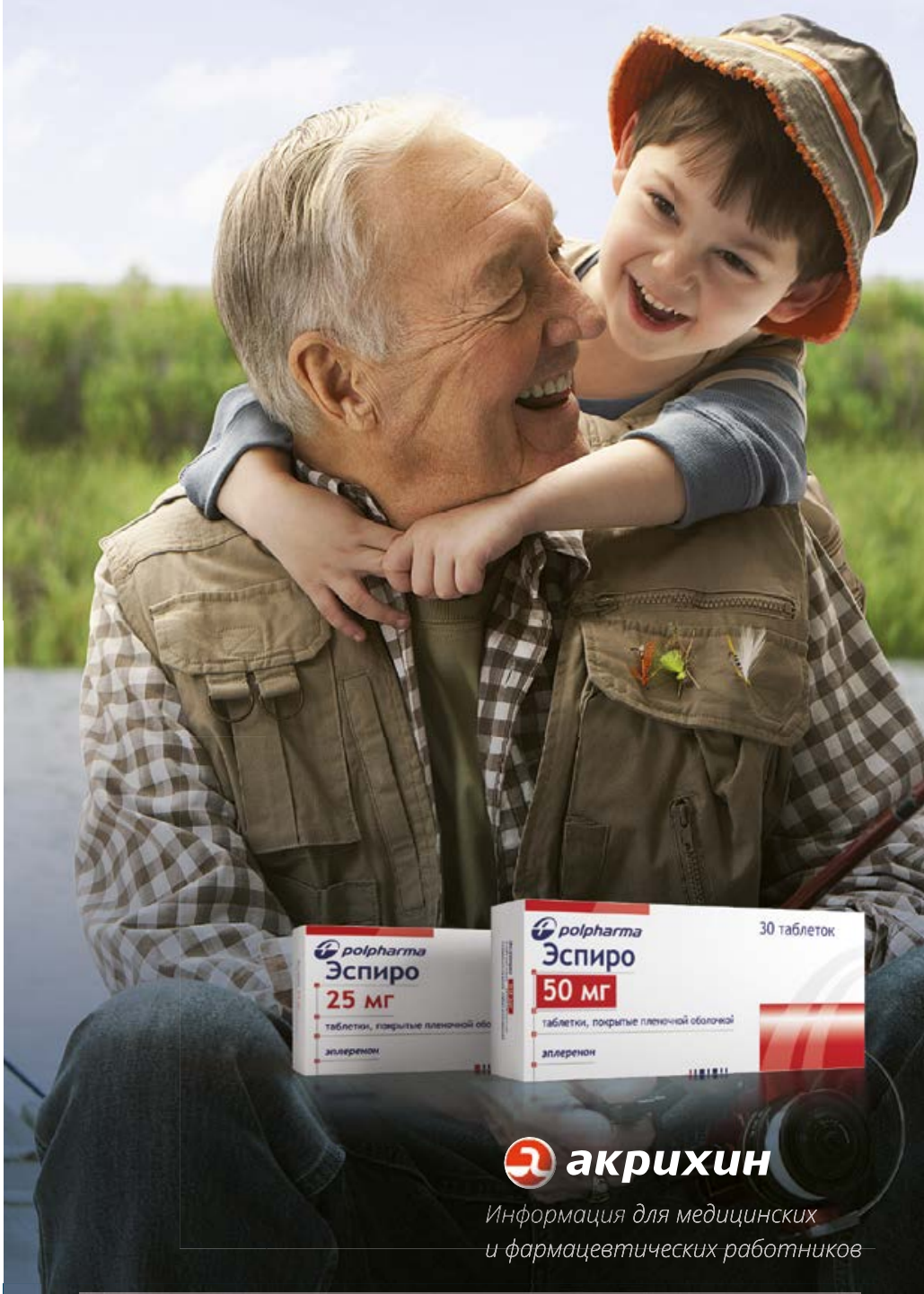

Снижает внезапную смертность на $1 / 3^{1}$

Снижает количество госпитализаций ${ }^{2}$

Улучшает функцию миокарда ${ }^{3}$

1 - Pitt B et d. Eur. J Heart Fail/ 2006: 8: 295-301.

2 - Zannad et al., N Engl J Med. (10.1056/NEJM oa 1009492) Novamber 14, 2010

3 - Udelson.JF. Et d., Circ. Heart Fail. 2010;3: 347-353

Производитель - фармацевтический завод «Польфарма» А0, Польша

AО «АКРИХИН», 142 450, Московская область, Ногинский район,

г. Старая Купавна, ул. Кирова, 29, телефон/факс (495) 702-95-03 
и сегоАня отложение мипопротеинов в матриксе клапана считается ключевым звеном этого заболевания [68]. Иммуногистохимические исслеАования демонстрируют колокализацию АТ II, АПФ и внеклеточного аполипопротеина в тканях хирургически удаменных АК [39]. Кроме того, посредством метода вестерн-блоттинга выявлена

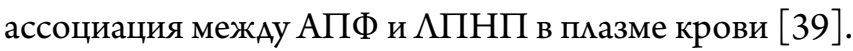

Таким образом, уже на ранних стаАиях КАС в клапане присутствуют все компоненты, необходимые Аля активации PAАС: осажАение в матриксе створок мипопротеинов с послеАующим их окислением провоцирует развитие интенсивной воспалительной реакции и фиброза, вследствие чего клапан инфильтрируется иммунными клетками [69], причем и мипопротеины, и мейкоциты являются источниками AT II-образующих ферментов. По мере активации РААС эти взаимосвязи, вероятно, начинают работать по принципу положительной обратной связи. Как известно, АТ II может усимивать синтез клетками протеогликанов [70]. Благодаря способности последних связывать мипопротеины $[71,72]$, а также свойству АТ II увеличивать продукцию клетками кислородных радикалов, процессы аккумумяции и окисления мипопротеинов в пораженном клапане постепенно усимиваются, что в свою очереАь веАет к усилению воспаления и еще большему увекичению мипиАной и мейкоцитарной инфильтрации. Аругими словами, формируется порочный круг: чем больше AT II накапиивается в тканях пораженного клапана, тем активнее протекают воспалительные и фиброзные реакции; в свою очереАь усимение этих процессов приводит к увеличению концентрации AT II (рис. 1).

\section{Прочие компоненты РААС}

и их возможная роль в клапанной кальцификации

В соответствии с современными взгляАами, РААС включает значительно больше компонентов, чем преАполагалось изначацьно. Помимо ренина, проренина, амьдостерона, АТ I/II, АПФ, АТ1-Р и АТ2-Р, а также ранее упомянутых АТ (1-12) и АT (1-25), в состав РАAC вхоАит множество пептиАов, таких как АТ A/ $(1-5) /(1-7) /(1-9) /(2-8) /(3-8)$, амаманАин, ангиопротектин и Ар. $[34,35,41]$. В целом их физиологические функции изучены хуже, чем таковые AT II. ПреАпомагается, что часть АТ-пептиАов преАставляет собой биологически инертные продукты АеграАации ангиотензиногена, AT I и AT II [41]. Тем не менее постепенно накапииваются доказательства того, что большинство этих соеАинений все же являются биоактивными и могут участвовать в модумяции функций РААС. Таким образом, они могут вносить определенный вклаА в процессы клапанной кальцификации. Аамее кратко рассматриваются функции наи- более изученных АТ-пептидов. Сводная информация по основным рассматриваемым соеАинениям привеАена на схеме (рис. 2).

Ангиотензин (1-7). Среди аругих недавно выявленных AT-пептидов функционацьные эффекты AT (1-7) изучены наиболее подробно. АТ (1-7) образуется при деградации AT II ики AT (1-9) [34]. Преобразование AT II в AT (1-7) происходит при участии открытого в 2000 гоАу АПФ2 [73], тогАа как переход АТ (1-9) в АТ (1-7) катамизируется АПФ [34]. Считается, что физиологические функции АТ (1-7) противоположны функциям АT II $[74,75]$. AT (1-7) взаимодействует с Mas-рецепторами (Mas-P) и передает сигналы, активирующие эндотекиальнопротективные, кардиопротективные, вазодилатирующие, антивоспалительные, антипролиферативные и антифиброгенные реакции $[34,35,41]$. Важное значение AT (1-7) и Mas-Р в подАержании сердечно-сосудистого гомеостаза продемонстрировано на Mas-Р-нокаутных мышах, подверженным развитию АГ и нарушению функции энАотелия, связанной с уменьшением экспрессии синтазы оксида азота и снижением производства оксиАа азота и увеличением концентрации радикалов кислорода [76]. Помимо прочего, система АПФ2/AТ (1-7)/Mas-Р не только активирует сигналы, противодействующие таковым системы АПФ/ATII/AT1-Р, но и препятствует Аействию AT II за счет усиления его Аеградации ферментом АПФ2 [74]. Важная ромь послеАнего поАтвержАается результатами исслеАований на АПФ2-дефицитных мышах [77, 78] и гипертензивных крысах [79], Аемонстрирующими развитие патологических изменений в серАцах животных при неАостатке АПФ2.

Примечательно, что в пораженных АК наряду с активацией АПФ/ATII/AT1-Р наблюдается резкое снижение экспрессии компонентов системы АПФ2/АТ (1-7)/Mas-P [80]. Таким образом, усиление неблагоприятного возАействия АТ II и гиперактивация РААС в тканях пораженных клапанов могут быть отчасти связаны со снижением уровней АПФ2 и АТ (1-7), а также пониженной экспрессией Mas-P и AT2-P [80]. Это открытие преАполагает, что система АПФ2/Анг (1-7)/Mas-P может стать перспективной терапевтической мишенью у больных КАС, поскольку она явмяется естественным ингибитором AT II [35]. С Аругой стороны, не все экс перименты демонстрируют положительное влияние АТ (1-7) на сердечно-сосудистую систему и его антагонизм с AT II [81-83]. Так, инфузии AT (1-7) или его антагониста А-779 не оказывали влияние на индуцированное АТ II хроническое повышение АА у крыс [81]. Кроме того, особенности функционирования системы АПФ2/АТ (1-7)/Mas-Р все еще не изучены Аолжным образом и имеются Аанные, что АТ (1-7) также может участвовать в ряде патологических процессов. Например, ввеАение 
Рисунок 1. Потенциальная роль РААС в патофизиологии КАС

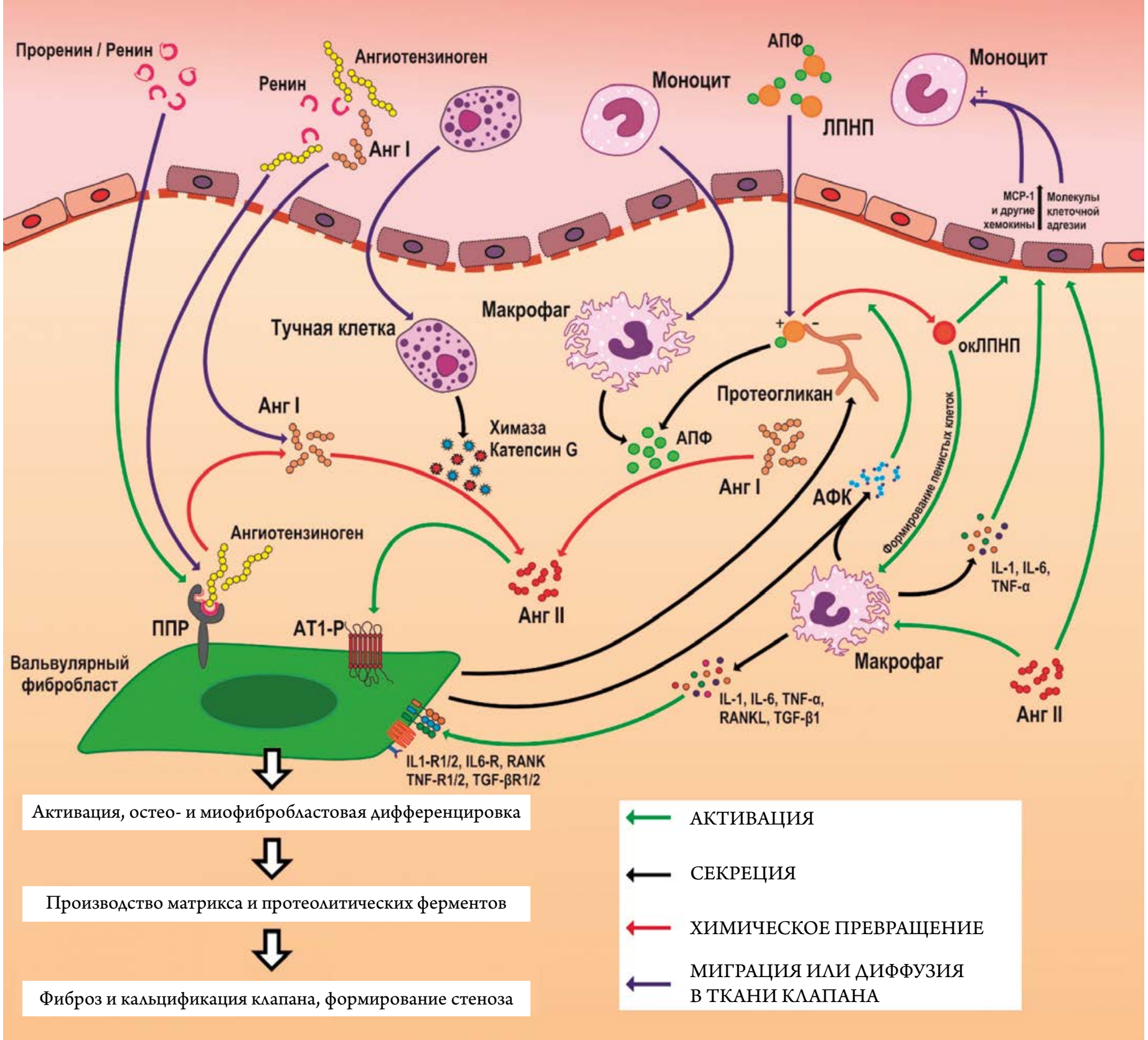

АнгI/II - ангиотензины I и II, АПФ - ангиотензинпревращающий фермент, AT 1-P - рецептор ангиотензина II типа 1,

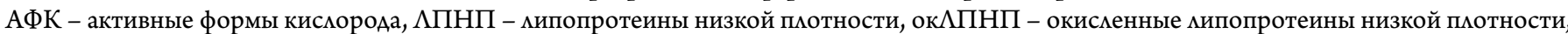
ПРP - (про)рениновый рецептор, IL-1/6 - интерлейкины-1 и -6, MCP-1 - моноцитарный хемотаксический белок-1, RANKL - лиганА рецептора-активатора ядерного фактора каппа- $\beta$, TGF- $\beta$ - трансформирующий ростовой фактор бета, TNF- $\alpha$ - фактор некроза опухоли альфа, IL1-R1/2 - рецепторы интерлейкина-1 типа 1 и 2, IL6-R - рецептор интерлейкина-6, RANKL - рецептор-активатор ядерного фактора каппа- $\beta$, TGF- $\beta$ R $1 / 2$ - рецепторы трансформирующего ростового фактора бета типа 1 и 2 , TNF-R1/2 - рецепторы фактора некроза опухоли типа 1 и 2.

подвергнутым субтотальной нефрэктомии крысам АТ (1-7) приводит к увекичению АА, фиброзу и гипертрофии серАца, на основании чего сделан вывод о возможном пагубном воздействии АТ (1-7) на сердечно-сосудистую систему при наличии почечной недостаточности [82]. В Аругом исследовании показано, что инфузия АТ (1-7) заметно ускоряет прогрессирующую диабетическую нефропатию у диабетических крыс, причем введение АТ (1-7) подопытным животным сопровожАается явной
Аисрегумяцией РААС, связанной с резким снижением экспрессии мРНК АПФ2, Mas-Р и AT2-Р, и увеличением уровней мРНК АПФ и АТ1-Р [83].

Ангиотензин (1-9). Аанный пептиА образуется при катализируемом АПФ2 расщеплении АТ I [73], его выявценные физиологические функции во многом аналогичны таковым АТ (1-7) $[84,85]$. Эксперименты in vitro и in vivo указывают на то, что AT (1-9) обладает выраженными антигипертензивными, антиокислительными, 
$\int$ овзоры

Рисунок 2. Основные компоненты РАAС и их физиологические функции

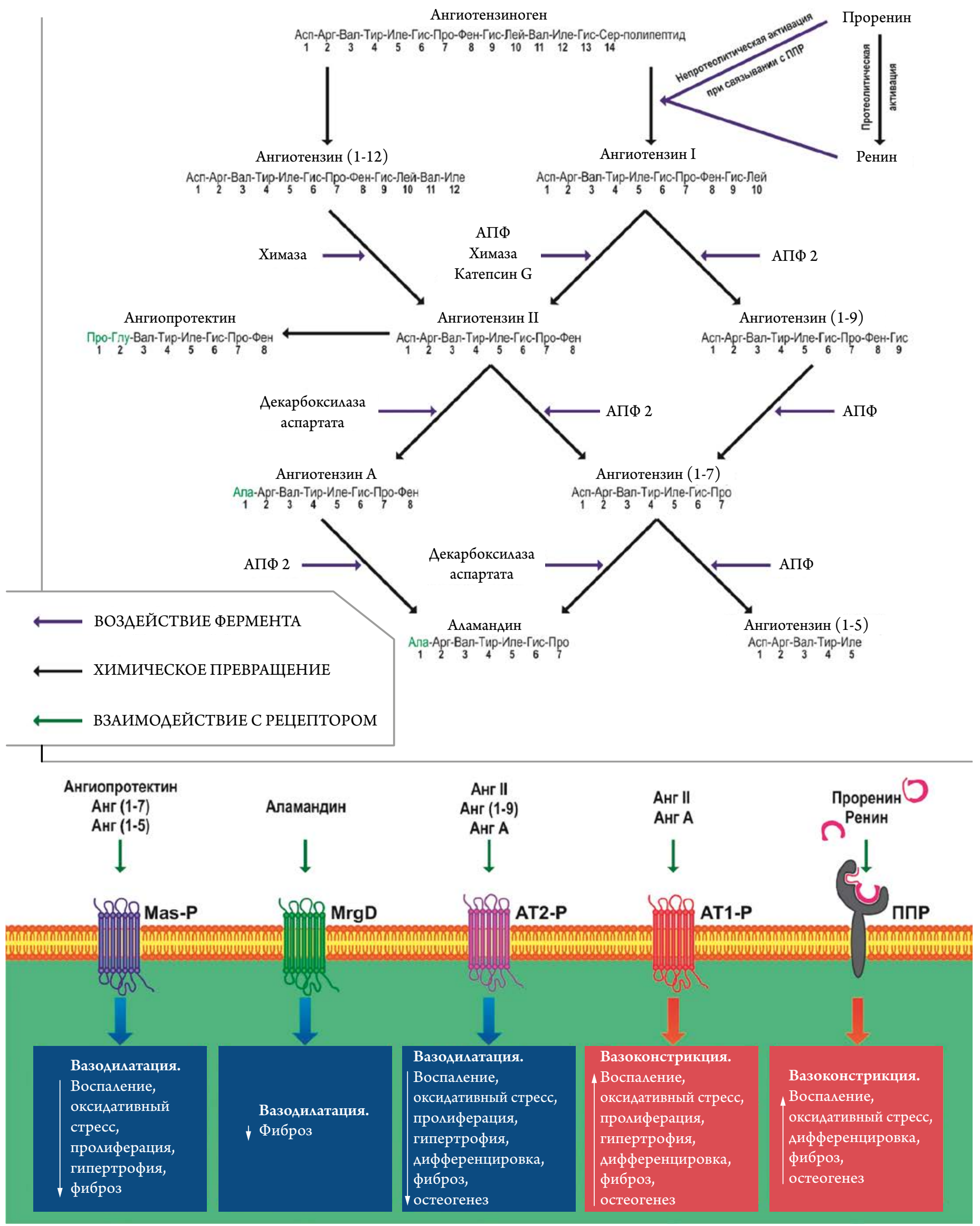

Анг - ангиотензин, АПФ - ангиотензинпревращающий фермент, АТ1-P - рецептор ангиотензина II типа 1,

AT2-P - рецептор ангиотензина II типа 2, Mas-P - mas-рецептор, MrgD - mas-зависимый G-белок-связанный рецептор типа D, ПРР - (про)рениновый рецептор. 
антипролиферативными, антифибротическими и антигипертрофическими свойствами [86-88]. Также показано, что АТ (1-9) подавмяет активность АПФ и снижает циркулирующие уровни AT II у гипертензивных крыс [87]. В отличие от АТ (1-7), функциональные эффекты AT (1-9) опосредуются не через Mas-P, а через AT2-P [87-90].

Ангиотензин (1-5). АТ (1-5) явцяется продуктом Аеградации АТ (1-7) и образуется при взаимодействии последнего с АПФ [91]. Сообщается, что АТ (1-5) стимулирует продукцию преАсерАного натрийуретического пептида у крыс через взаимодействие с Mas-P и активацию сигнального каскада PI3K/Akt/NOS, причем его секреторный эффект аналогичен таковому АТ (1-7) и АТ (1-9) [91]. Хотя функции АТ (1-5) изучены слабо, суАя по всему, они во многом подобны таковым АТ (1-7) и АТ (1-9).

Аламандин. По своим физиологическим функциям аламандин сходен с АТ (1-7) и АТ (1-9), однако функциональные эффекты данного пептида опосредуются через его собственный специфический рецептор $\mathrm{MrgD}$ [92-94]. Эксперименты на животных показывают, что аламандин обладает вазодикатирующими и гипотензивными свойствами, а также препятствует фиброзу $[93,95]$. В то же время он не влияет на процессы пролиферации в культивируемых опухолевых кметках человека [93]. Аламандин образуется при катализируемой АПФ2 деградации АТ А, а также из АТ (1-7) путем ферментативного декарбоксимирования аспарагиновой кислоты $[34,93]$. Стоит отметить, что он не взаимодействует с Mas-P и AT2-P [93].

Ангиопротектин. Ангиопротектин преАставцяет собой еще один пептиА РАAC, образующийся из АТ II ферментативным путем [96]. Его функции практически не изучены. Известно, что он вызывает вазодикатацию через взаимодействие с Mas-P [96].

Ангиотензин А. Аанный пептид открыт в 2007 году [97]. Установлено, что он присутствует в плазме здоровых АюАей в концентрации, составмяющей порядка $20 \%$ концентрации АТ II. При этом у мюАей, страдающих почечной недостаточностью на конечной стадии, отношение АТ А к АТ II резко увеличивается [97]. По всей видимости, АТ А образуется из АТ II путем декарбоксилирования аспарагиновой кислоты декарбоксилазой аспартата, выделяемой мононукмеарными мейкоцитами [97]. Накопившаяся к настоящему моменту информация свиАетельствует о том, что функциональная роль АТ А может быть сходна с таковой его предшественника $[34,92]$. Как и AT II, AT А индуцирует вазоконстрикцию и стимумирует повышение АA, хотя и со значительно меньшей эффективностью [95, 97-99]. Также АТ А усиливает процессы клеточной пролиферации, причем он оказывает более выраженный эффект, чем AT II [92]. Считается, что основные эффекты АТ А опосредуются через АТ 1-Р [92], хотя некоторые исследователи предполагают существование еще неоткрытого рецептора Аля Аанного пептида [99]. Также АТ А может связываться с АТ2-Р, а его аффинность к этому рецептору анамогична [98] или Ааже выше таковой AT II [97]. Тем не менее, физиологическая роль взаимодействия АТ А с АТ2-Р не изучена [92].

Итак, основываясь на вышесказанном, следует подчеркнуть, что РАAС не явмяется простым минейным каскаАом и включает множество сложно взаимодействующих компонентов. Учитывая слабую изученность большинства Анг-пептидов, трудно сАелать однозначный вывоА касательно их потенциальной роли в патогенезе КАС. Тем не менее, с учетом того, что многие из них биоактивны и оказывают заметное влияние на ремоделирование тканей серАца и функции серАечно-сосудистой системы в целом, имеется сильное основание предполагать их участие в патофизиологии кмапанной кальцификации. СуАя по всему, такие пептиды, как AT II и, возможно, АT A, ускоряют фиброзно-скиеротическое ремоделирование и минерализацию створок, в то время как Аругие компоненты РААС, включая АТ (1-5) / (1-7) / (1-9) и аламандин, могут им противодействовать, оАнако эта гипотеза нужАается в экспериментальной проверке.

\section{МоАумяция активности РААС в управмении патогенезом КАС}

\section{Влияние ингибиторов АПФ}

и антагонистов АТ1-Р на прогрессию КАС

Сегодня РААС остается главной терапевтической мишенью в поиске медикаментозного мечения КАС [35]. Результаты экспериментальных работ на животных показывают, что ингибирование РААС способствует уменьшению неблагоприятных гистопатологических событий, включающих развитие эндотелиальной дисфункции и фиброза, накопление кипидов и формирование кейкоцитарных инфильтратов $[49,100,101]$. Кроме того, использование иАПФ способствует замеАлению гемоАинамической прогрессии КАС у подопытных кроликов [100].

В свою очередь результаты кминических исследований по эффективности иАПФ в замеАлении прогрессирования КАС остаются спорными. К настоящему моменту проведено три маломасштабных рандомизированных контролируемых испытания, оценивающих безопасность и эффективность иАПФ [102-104] в терапии КАС. Результаты исследований свидетельствуют о том, что иАПФ хорошо переносятся пациентами Ааже с тяжеАым стенозом, а их применение способствует улучшению гемодинамических параметров и замедмению гемодинамической прогрессии КАС. Тем не менее, Амя подтверж- 
Аения этих выводов и определения их клинической значимости требуются крупные проспективные испытания, которые пока еще не проводимись.

В настоящее время опубликованы три ретроспективных исследования, согласно которым при терапии КАС могут быть помезны блокаторы АТ 1-Р [105-107]. Важно отметить, что согласно Аанным оАного из исслеАований именно БРА, а не иАПФ замеАляют прогрессию КАС и уменьшают вероятность неблагоприятных кминических исходов [105]. Эти выводы ПодтвержАаются резукьтатами Аругого ретроспективного исследования, которое также указывает на неэффективность иАПФ в мечении КАС [108]. С Аругой стороны, ретроспективный анализ 123 пациентов, которым АважАы с интервалом в 2,5 года выполнялась электронно-лучевая компьютерная томография, показац, что у принимавших иАПФ пациентов скорость камьцификации АК оказалась значительно ниже, чем у пациентов, не получавших такого мечения [109]. Кроме того, результаты недавнего наблюдательного исследования [110], включающие анализ более 2117 пациентов с аортальным стенозом, показывают, что терапия иАПФ и БРА связана с мучшей выживаемостью и меньшим риском неблагоприятных серАечнососуаистых событий у больных КАС.

Итак, как уже было отмечено выше, результаты приведенных клинических исслеАований довольно противоречивы. Следует учесть, что они проведены на небольших выборках и этого явно недостаточно, чтобы сделать оАнозначные выводы. Только крупные Аолгосрочные рандомизированные исследования помогут разобраться в имеющихся противоречиях и четко установить терапевтические эффекты иАПФ и БРА на прогрессию КАС.

\section{Терапия сопутствующих КАC} патологий через модулячию РААС

Несмотря на то, что сегодня не разработано методов неинвазивного мечения КАС, меАикаментозная терапия играет большую роль в коррекции сопутствующих патомогий у пациентов с этим заболеванием. Фактически, большая часть неблагоприятных кминических исходов у пациентов с КАС связана с гипертрофией и Аисфункцией $\Lambda Ж$, которые возникают в ответ на стенозирование аортального отверстия и усиливаются системной АГ. Таким образом, потенциальные цели консервативного мечения, направменного на умучшение клинических исходов у пациентов с КАС, Аолжны включать не только контроль за развитием патологических изменений в самом клапане, но и терапию ряда Аругих патологических состояний серАечно-сосудистой системы, таких как АГ и гипертрофия $\Lambda Ж$.

Известно, что ингибирование РААС способствует снижению АА и уменьшению гипертрофии $\Lambda Ж$, что позволяет улучшить показатели выживаемости и Аругие важные клинические события у пациентов с $\mathrm{CH}$ и сниженной $Ф \mathrm{~B}$ $\Lambda Ж$ [7]. Также при снижении АА и уменьшении массы $\Lambda Ж$ уменьшаются и механические нагрузки на створки, что теоретически может способствовать замеАлению процессов кальцификации АК. Известно, что активация вальвулярных интерстициальных клеток, их переход к миофибробластическому и остеобластическому фенотипам, а также начало процессов неадаптивного ремоделирования тканей отчасти регулируются свойствами матрикса и интенсивностью механического воздействия $[111,112]$. Эксперимент ex vivo c растяжением в биореакторе фрагментов створок АК свиньи Аемонстрирует, что при увекичении механической нагрузки на ткани сверх физиологической нормы повышается экспрессия остеоиндуктивных цитокинов и белков костного матрикса, усиливаются процессы апоптоза и кальцификации [113]. Таким образом, снижение Аавления крови и уменьшение нагрузок на створки у бомьных КАС, возможно, будет способствовать снижению интенсивности аналогичных процессов в тканях пораженных клапанов.

Учитывая Аанные китературных источников, можно сАелать слеАующий вывоА: несмотря на то, что ингибирование РАAС не может быть рекомендовано в качестве специфического мечения КАС, разработка терапии на основе ее модумяторов кажется наиболее перспективным направмением, поскольку бцагодаря такому подходу можно возАействовать сразу на несколько патологических процессов, включая кмапанную кальцификацию, АГ и гипертрофию $\Lambda Ж$. Важно подчеркнуть, что обеспокоенность по поводу риска значительных гипотензивных эффектов у больных КАС, вызванных приемом иАПФ и БРА, по всей виАимости, необоснована: большинство пациентов, включая больных с Аисфункцией $\Lambda Ж$, переносят мечение иАПФ и БРА без значимой гипотензии ими иных побочных эффектов [102-104, 110, 114], а прием таких препаратов не связан с увекичением показателей смертности от внезапной серАечной смерти или иных серАечно-сосудистых событий у пациентов с КАС [115]. Таким образом, основываясь на имеющихся Аанных, можно говорить о высокой степени безопасности ингибиторов РААС при терапии бомьных КАС, оАнако, как уже отмечалось выше, Аля подтвержАения этих выводов требуются крупномасштабные исследования.

\section{Пути модуляции активности РААС влечении КАС}

Стоит отметить, что существует несколько путей модумяции активности РААС в сердечных клапанах. В первую очередь сюда относятся препараты, снижающие эффективность передачи сигналов системой АПФ/ATII/AT1-P за счет снижения производства AT II или блокирования AT1-Р. К ним относятся рассмотренные ранее иАПФ и БРА. Но, вполне возможно, что только мишь иАПФ и БРА неАостаточно Аля управмения активацией РААС 
в пораженном клапане. Так, переход AT I в AT II может опосредоваться химазой, активность которой не поАавмяется иАПФ, а каталитическая эффективность превосходит таковую АПФ примерно в 20 раз [116]. Причем химаза не только способствует мокальному накопмению АТ II в тканях сердца и пораженных клапанах, но и участвует в процессах активации профиброгенных факторов и протеолитических ферментов [117]. Согласно современным Аанным, ингибирование химазы может иметь значительные терапевтические преимущества переА иАПФ Аля остановки прогрессирования ряда СС3, вкмючая клапанную кальцификацию [117]. Эффективность БРА также остается поА вопросом. Хотя бцокировка АТ1-Р препятствует передачи сигналов АТ II, могут существовать и Аругие АнгпептиАы, обладающие сходными с АТ II свойствами, чьи функциональные эффекты опосредуются через рецепторы, отмичные от АТ1-Р. Потенциально, к таким АТ-пептидам могут относиться АТ А и АТ (3-8) [92, 99].

Обращает на себя внимание и Аругой компонент РААС - ПРР. Поскольку Аанный рецептор фактически находится у истока каскаАа РААС, его блокирование может привести к уменьшению активности всей системы. Более того, использование антагонистов ПРР может уменьшить интенсивность воспалительных, фибротических и остеогенных реакций в клапане независимо от активации каскаАа РААС, поскольку ПРР инАуцирует передачу сигналов ERK1/2, p38 MAPK, PI3K [34, 118], а также явмяется важным компонентом сигнацьного пути Wnt/ $\beta$-catenin [34, $119]$, играющего кмючевую роль в Аифференцировке остеобластов и активации остеогенеза в клапане [68].

Наконец, перспективными мишенями фармакотерапии КАС в будущем могут стать и естественные антагонисты системы АПФ/ATII/AT1-P, такие как AT $(1-5) /(1-7) /(1-9)$ и аламандин. Тем не менее, в настоящее время функции этих соеАинений исследованы слабо и требуют Аополнитемьного изучения.

\section{Закмючение}

Ренин-ангиотензин-ацьдостероновая система преАставляет собой сложную сеть переплетающихся молекумярных путей, она участвует в регумяции множества процессов, имеющих первостепенное значение Аля подАержания внутреннего гомеостаза организма на клеточном, тканевом и системном уровнях. Аисрегумяция РАAС тесно связана с разАичными патологиями, оАной из которых явмяется камьцификация АК. Это декает РААС привлекательной терапевтической мишенью Аля разработки фармакотерапии КАС, однако наличие в этой системе большого числа сложно взаимодействующих и к тому же плохо изученных компонентов сильно затрудняет предсказание терапевтических результатов. В настоящее время понимание роли РААС в патофизиологии КАС остается Аовольно
Всегда на

шаг впереди

\section{КораксСан}

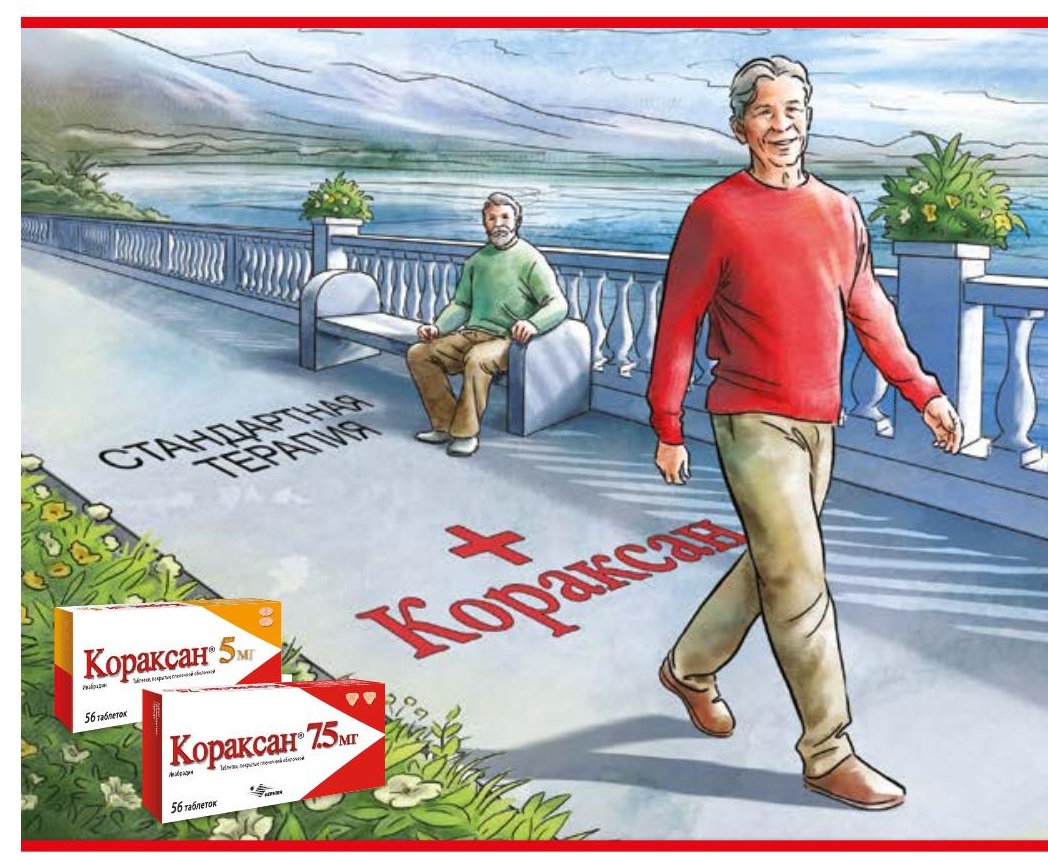

Уменьшает симптомы, увеличивает
переносимость нагрузки при ИБС и ХСН ${ }^{1}$

Снижает риск инфаркта миокарда при ИБС с дисфункцией левого желудочка ${ }^{1}$

Улучшает прогноз при ХСН ${ }^{1}$
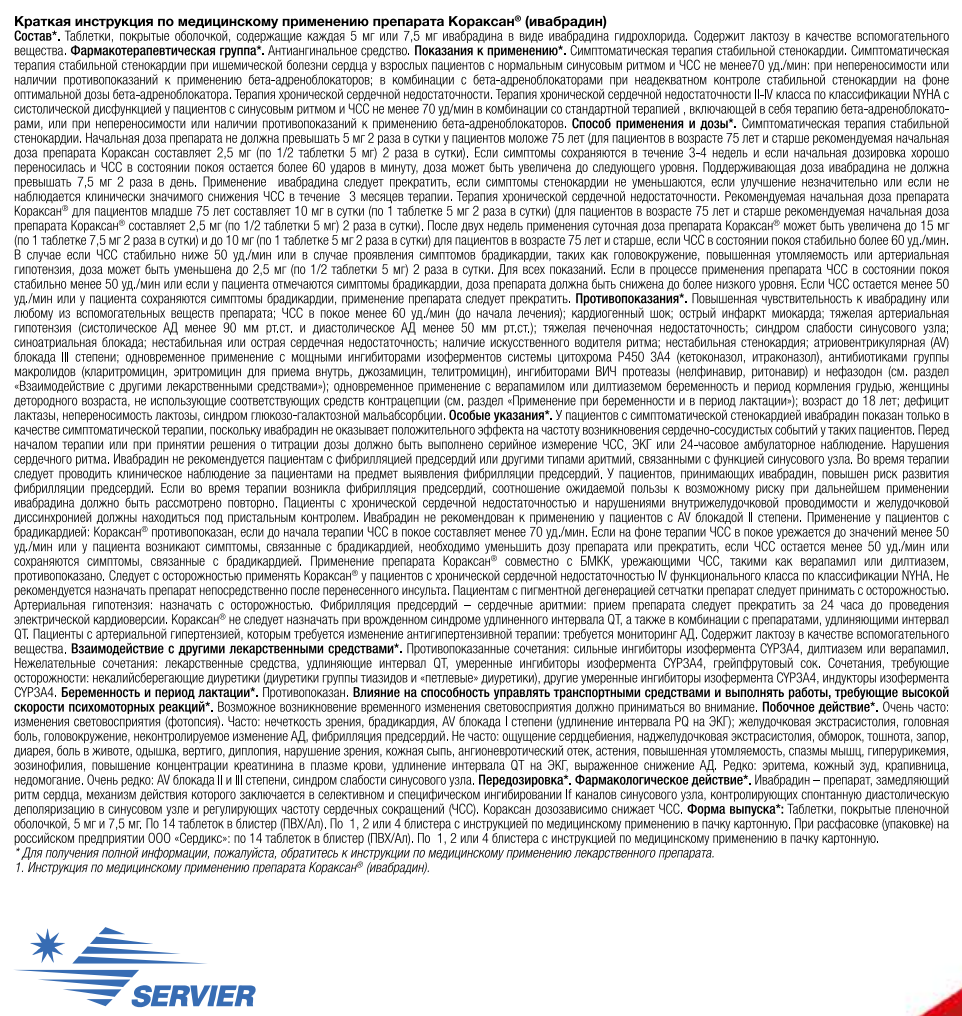

Материал предназначен для специалистов здравоохранения. AO «Сервье»: Россия, 125047, Москва, ул. Лесная, д. 7. Тел.: +7 4959370700 
ограниченным, а результаты кминических исследований ее ингибиторов весьма неоднозначны. Сегодня модумя ция активности РААС посреАством применения иАПФ и БРА не может рекомендоваться в качестве мечения КАС, но, вероятно, в будущем эта ситуация может измениться с появлением крупномасштабных проспективных исследований, позволяющих установить точные терапевтические эффекты и оценить кминическую значимость уже существующих моАуляторов РААС. С Аругой стороны, требуются новые фундаментальные исследования Аля опредемения роли неАавно открытых компонентов РААС в клапанном гомеостазе и процессах камьцификации, которые могут стать кАючом к разработке эффективных методов фармакотерапии КАС и Аругих СС3.

\section{МИТЕРATУPA/REFERENCES}

1. Lindman BR, Clavel M-A, Mathieu P, Iung B, Lancellotti P, Otto CM et al. Calcific aortic stenosis. Nature Reviews Disease Primers. 2016;2(1):16006. DOI: $10.1038 /$ nrdp.2016.6

2. Authors/Task Force Members, Vahanian A, Alfieri O, Andreotti F, Antunes MJ, Barón-Esquivias $\mathrm{G}$ et al. Guidelines on the management of valvular heart disease (version 2012). European Heart Journal. 2012;33(19):2451-96. DOI: 10.1093/eurheartj/ehs109

3. d'Arcy JL, Prendergast BD, Chambers JB, Ray SG, Bridgewater B. Valvular heart disease: the next cardiac epidemic. Heart. 2011;97(2):91-3. DOI: 10.1136/hrt.2010.205096

4. Iung B, Vahanian A. Degenerative calcific aortic stenosis: a natural history. Heart. 2012;98(Suppl 4):iv7-13. DOI: 10.1136/ heartjnl-2012-302395

5. Osnabrugge RLJ, Mylotte D, Head SJ, Van Mieghem NM, Nkomo VT, LeReun CM et al. Aortic Stenosis in the Elderly: disease prevalence and number of candidates for transcatheter aortic valve replacement: a meta-analysis and modeling study. Journal of the American College of Cardiology. 2013;62(11):1002-12.DOI: 10.1016/j.jacc.2013.05.015

6. Thaden JJ, Nkomo VT, Enriquez-Sarano M. The Global Burden of Aortic Stenosis. Progress in Cardiovascular Diseases. 2014;56(6):56571. DOI: 10.1016/j.pcad.2014.02.006

7. Marquis-Gravel G, Redfors B, Leon MB, Généreux P. Medical Treatment of Aortic Stenosis. Circulation. 2016;134(22):1766-84. DOI: 10.1161/CIRCULATIONAHA.116.023997

8. Salas MJ, Santana O, Escolar E, Lamas GA. Medical Therapy for Calcific Aortic Stenosis. Journal of Cardiovascular Pharmacology and Therapeutics. 2012;17(2):133-8. DOI: 10.1177/1074248411416504

9. Baumgartner H, Falk V, Bax JJ, De Bonis M, Hamm C, Holm PJ et al. 2017 ESC/EACTS Guidelines for the management of valvular heart disease. European Heart Journal. 2017;38(36):2739-91. DOI: 10.1093/eurheartj/ehx391

10. Lindman BR, Bonow RO, Otto CM. Current Management of Calcific Aortic Stenosis. Circulation Research. 2013;113(2):223-37. DOI: 10.1161/CIRCRESAHA.111.300084

11. Nishimura RA, Otto CM, Bonow RO, Carabello BA, Erwin JP, Fleisher LA et al. 2017 AHA/ACC Focused Update of the 2014 AHA/ACC Guideline for the Management of Patients with Valvular Heart Disease: A Report of the American College of Cardiology/ American Heart Association Task Force on Clinical Practice Guidelines. Circulation. 2017;135(25):e1159-95. DOI: 10.1161/ CIR.0000000000000503

12. Gulyaev N.I., Varavin N.A., Korovin A.E., Kuznetsov V.V., Yakovlev V.V., Gordienko A.V. Modern aspects of pathogenesis of calcification of the aortic valve. Bulletin of Saint-Petersburg State University. 2016;3:20-34. [Russian: Гумяев Н.И., Варавин Н.А., Коровин А.Е., Кузнецов В. В., Яковмев В.В., Гордиенко А.В. Современные аспекты патогенеза

\section{Список сокращений}

АТ - ангиотензин, АГ - артериальная гипертензия, АПФ ангиотензинпревращающий фермент, AT1-P и АT2-P рецепторы AII типа 1 и 2, БРА - блокаторы рецепторов ангиотензина, КАС - кальцинирующий аортальный стеноз, ПРP - (про) рениновый рецептор, Mas-P - Mas-рецептор.

Конфликт интересов не заявлен.

Работа выполнена в рамках комплексной программы фундаментальных научных исследований СО РАН по фундаментальной теме НИИ КПССЗ № 0546-2015-0011 «Патогенетическое обоснование разработки имплантатов дяя сердечно-сосудистой хирургии на основе биосовместимых материалов, с реализацией пациент-ориентированного подхода с использованием математического моделирования, тканевой инженерии и геномных предикторов».

кальциноза аортальных полукуний (обзор митературы). Вестник СПбГУ. 2016;3:20-34]. DOI: 10.21638/11701/spbu11.2016.302

13. Pacurari M, Kafoury R, Tchounwou PB, Ndebele K. The ReninAngiotensin-Aldosterone System in Vascular Inflammation and Remodeling.InternationalJournal ofInflammation.2014;2014:689360. DOI: $10.1155 / 2014 / 689360$

14. Cao W, Hu N, Yuan Y, Cheng J, Guo X, Wang Y et al. Effects of Tilianin on Proliferation, Migration and TGF- $\beta /$ Smad Signaling in Rat Vascular Smooth Muscle Cells Induced with Angiotensin II: Pharmacological effect of Talinin on rat vascular smooth muscle cells. Phytotherapy Research. 2017;31(8):1240-8. DOI: 10.1002/ptr.5846

15. Chen T, Li M, Fan X, Cheng J, Wang L. Sodium Tanshinone IIA Sulfonate Prevents Angiotensin II-Induced Differentiation of Human Atrial Fibroblasts into Myofibroblasts. Oxidative Medicine and Cellular Longevity. 2018;2018:6712585. DOI: 10.1155/2018/6712585

16. Wu X, Liu Y, An J, Li J, Lv W, Geng S et al. Piperlongumine inhibits angiotensin II-induced extracellular matrix expression in cardiac fibroblasts. Journal of Cellular Biochemistry. 2018;119(12):10358-64. DOI: $10.1002 /$ jcb.27379

17. Barhoumi T, Fraulob-Aquino JC, Mian MOR, Ouerd S, IdrisKhodja N, Huo K-G et al. Matrix metalloproteinase-2 knockout prevents angiotensin II-induced vascular injury. Cardiovascular Research. 2017;113(14):1753-62. DOI: 10.1093/cvr/cvx115

18. Kong J, Zhang Y, Liu S, Li H, Liu S, Wang J et al. Melatonin attenuates angiotensin II-induced abdominal aortic aneurysm through the down-regulation of matrix metalloproteinases. Oncotarget. 2017;8(9):14283-93. DOI: 10.18632/oncotarget.15093

19. Guo F, Chen X-L, Wang F, Liang X, Sun Y-X, Wang Y-J. Role of Angiotensin II Type 1 Receptor in Angiotensin II-Induced Cytokine Production in Macrophages. Journal of Interferon \& Cytokine Research. 2011;31(4):351-61. DOI: 10.1089/jir.2010.0073

20. Manuneedhi Cholan P, Cartland SP, Dang L, Rayner BS, Patel S, Thomas SR et al. TRAIL protects against endothelial dysfunction in vivo and inhibits angiotensin-II-induced oxidative stress in vascular endothelial cells in vitro. Free Radical Biology and Medicine. 2018;126:341-9. DOI: 10.1016/j.freeradbiomed.2018.08.031

21. Tian H, Yu D, Hu Y, Zhang P, Yang Y, Hu Q et al. Angiotensin II upregulates cyclophilin A by enhancing ROS production in rat cardiomyocytes. Molecular Medicine Reports. 2018;18(5):4349-55. DOI: 10.3892/mmr.2018.9448

22. Han C, Liu J, Liu X, Li M. Angiotensin II induces C-reactive protein expression through ERK1/2 and JNK signaling in human aortic endothelial cells. Atherosclerosis. 2010;212(1):206-12. DOI: 10.1016/j. atherosclerosis.2010.05.020

23. Ruiz-Ortega M, Ruperez M, Lorenzo O, Esteban V, Blanco J, Mezzano S et al. Angiotensin II regulates the synthesis of proinflam- 
matory cytokines and chemokines in the kidney. Kidney International. 2002;82:S12-22. DOI: 10.1046/j.1523-1755.62.s82.4.x

24. Osako MK, Nakagami H, Shimamura M, Koriyama H, Nakagami F, Shimizu $\mathrm{H}$ et al. Cross-Talk of Receptor Activator of Nuclear Factor$\mathrm{B}$ Ligand Signaling With Renin-Angiotensin System in Vascular Calcification. Arteriosclerosis, Thrombosis, and Vascular Biology. 2013;33(6):1287-96. DOI: 10.1161/ATVBAHA.112.301099

25. Pueyo ME, Gonzalez W, Nicoletti A, Savoie F, Arnal JF, Michel JB. Angiotensin II stimulates endothelial vascular cell adhesion molecule-1 via nuclear factor-kappaB activation induced by intracellular oxidative stress. Arteriosclerosis, Thrombosis, and Vascular Biology. 2000;20(3):645-51. DOI: 10.1161/01.atv.20.3.645

26. Oparil S, Acelajado MC, Bakris GL, Berlowitz DR, Cífková R, Dominiczak AF et al. Hypertension. Nature Reviews Disease Primers. 2018;4(1):18014. DOI: $10.1038 /$ nrdp.2018.14

27. Montecucco F, Pende A, Mach F. The Renin-Angiotensin System Modulates Inflammatory Processes in Atherosclerosis: Evidence from Basic Research and Clinical Studies. Mediators of Inflammation. 2009; 2009:752406. DOI: 10.1155/2009/752406

28. Sata M, Fukuda D. Crucial role of renin-angiotensin system in the pathogenesis of atherosclerosis. The Journal of Medical Investigation. 2010;57(1-2):12-25. DOI: $10.2152 /$ jmi.57.12

29. George AJ, Thomas WG, Hannan RD. The renin-angiotensin system and cancer: old dog, new tricks. Nature Reviews Cancer. 2010;10(11):745-59. DOI: $10.1038 /$ nrc2945

30. Ishikane S, Takahashi-Yanaga F. The role of angiotensin II in cancer metastasis: Potential of renin-angiotensin system blockade as a treatment for cancer metastasis. Biochemical Pharmacology. 2018; 151:96103. DOI: $10.1016 /$ j.bcp.2018.03.008

31. Chu KY, Leung PS. Angiotensin II in type 2 diabetes mellitus. Current Protein \& Peptide Science. 2009;10(1):75-84. DOI: 10.2174/138920309787315176

32. Ribeiro-Oliveira AJr, Nogueira AI, Pereira RM, Boas WW, Dos Santos RA, Simões e Silva AC. The renin-angiotensin system and diabetes: An update. Vascular Health and Risk Management. 2008;4(4):787-803. DOI: 10.2147/VHRM.S1905

33. Remuzzi G, Perico N, Macia M, Ruggenenti P. The role of reninangiotensin-aldosterone system in the progression of chronic kidney disease. Kidney International. 2005;99:S57-65. DOI: 10.1111/j.15231755.2005.09911.x

34. Balakumar P, Jagadeesh G. A century old renin-angiotensin system still grows with endless possibilities: AT1 receptor signaling cascades in cardiovascular physiopathology. Cellular Signalling. 2014;26(10):214760. DOI: $10.1016 /$ j.cellsig.2014.06.011

35. Peltonen T, Ohukainen P, Ruskoaho H, Rysä J. Targeting vasoactive peptides for managing calcific aortic valve disease. Annals of Medicine. 2017;49(1):63-74. DOI: 10.1080/07853890.2016.1231933

36. Karnik SS, Unal H, Kemp JR, Tirupula KC, Eguchi S, Vanderheyden $\mathrm{PML}$ et al. International Union of Basic and Clinical Pharmacology. XCIX. Angiotensin Receptors: Interpreters of Pathophysiological Angiotensinergic Stimuli. Pharmacological Reviews. 2015;67(4):754819. DOI: $10.1124 / \mathrm{pr} .114 .010454$

37. Helske S, Lindstedt KA, Laine M, Mäyränpää M, Werkkala K, Lommi J et al. Induction of local angiotensin II-producing systems in stenotic aortic valves. Journal of the American College of Cardiology. 2004;44(9):1859-66. DOI: 10.1016/j.jacc.2004.07.054

38. Peltonen T, Näpänkangas J, Vuolteenaho O, Ohtonen P, Soini Y, Juvonen $\mathrm{T}$ et al. Apelin and its receptor APJ in human aortic valve stenosis. The Journal of Heart Valve Disease. 2009; 18(6):644-52. PMID: 20099713

39. O’Brien KD, Shavelle DM, Caulfield MT, McDonald TO, OlinLewis K, Otto CM et al. Association of angiotensin-converting enzyme with low-density lipoprotein in aortic valvular lesions and in human plasma. Circulation. 2002;106(17):2224-30. DOI: 10.1161/01. cir.0000035655.45453.d2

40. Li XC, Zhuo JL. Nuclear factor- $\mathrm{kB}$ as a hormonal intracellular signaling molecule: focus on angiotensin II-induced cardiovascular and renal injury: Current Opinion in Nephrology and Hypertension. 2008;17(1):37-43. DOI: 10.1097/MNH.0b013e3282f2903c
41. Zablocki D, Sadoshima J. Angiotensin II and Oxidative Stress in the Failing Heart. Antioxidants \& Redox Signaling. 2013;19(10):1095109. DOI: 10.1089 /ars.2012.4588

42. Liberman M, Bassi E, Martinatti MK, Lario FC, Wosniak J, Pomerantzeff PMA et al. Oxidant Generation Predominates Around Calcifying Foci and Enhances Progression of Aortic Valve Calcification. Arteriosclerosis, Thrombosis, and Vascular Biology. 2008;28(3):46370. DOI: 10.1161/ATVBAHA.107.156745

43. Miller JD, Chu Y, Brooks RM, Richenbacher WE, Peña-Silva R, Heistad DD. Dysregulation of Antioxidant Mechanisms Contributes to Increased Oxidative Stress in Calcific Aortic Valvular Stenosis in Humans. Journal of the American College of Cardiology. 2008;52(10):843-50. DOI: 10.1016/j.jacc.2008.05.043

44. Rajamannan N. Role of Oxidative Stress in Calcific Aortic Valve Disease: From Bench to Bedside - The Role of a Stem Cell Niche. In: Oxidative Stress and Chronic Degenerative Diseases - A Role for Antioxidants Morales-Gonzalez JA, editor -Croatia: InTech;2013.

45. Morgan MJ, Liu Z. Reactive oxygen species in TNF $\alpha$-induced signaling and cell death. Molecules and Cells. 2010;30(1):1-12. DOI: 10.1007/ s10059-010-0105-0

46. BelhadjSlimenI,NajarT,GhramA,DabbebiH,BenMradM,Abdrabbah $\mathrm{M}$. Reactive oxygen species, heat stress and oxidative-induced mitochondrial damage. A review. International Journal of Hyperthermia. 2014;30(7):513-23. DOI: 10.3109/02656736.2014.971446

47. Xie C, Shen Y, Hu W, Chen Z, Li Y. Angiotensin II promotes an osteoblast-like phenotype in porcine aortic valve myofibroblasts. Aging Clinical and Experimental Research. 2016;28(2):181-7. DOI: $10.1007 / \mathrm{s} 40520-015-0408-2$

48. Fujisaka T, Hoshiga M, Hotchi J, Takeda Y, Jin D, Takai S et al. Angiotensin II promotes aortic valve thickening independent of elevated blood pressure in apolipoprotein-E deficient mice. Atherosclerosis. 2013;226(1):82-7. DOI: 10.1016/j.atherosclerosis.2012.10.055

49. Arishiro K, Hoshiga M, Negoro N, Jin D, Takai S, Miyazaki M et al. Angiotensin Receptor-1 Blocker Inhibits Atherosclerotic Changes and Endothelial Disruption of the Aortic Valve in Hypercholesterolemic Rabbits. Journal of the American College of Cardiology. 2007;49(13):1482-9. DOI: 10.1016/j.jacc.2006.11.043

50. Masuda C, Dohi K, Sakurai Y, Bessho Y, Fukuda H, Fujii S et al. Impact of Chronic Kidney Disease on the Presence and Severity of Aortic Stenosis in Patients at High Risk for Coronary Artery Disease. Cardiovascular Ultrasound. 2011;9(1):31. DOI: 10.1186/1476-71209-31

51. Rieck ÅE, Cramariuc D, Boman K, Gohlke-Bärwolf C, Staal EM, Lønnebakken MT et al. Hypertension in Aortic Stenosis: Implications for Left Ventricular Structure and Cardiovascular Events. Hypertension. 2012;60(1):90-7. DOI: 10.1161/ HYPERTENSIONAHA.112.194878

52. Perkovic V, Hunt D, Griffin SV, du Plessis M, Becker GJ. Accelerated Progression of Calcific Aortic Stenosis in Dialysis Patients. Nephron Clinical Practice. 2004;94(2):c40-5. DOI: 10.1159/000071280

53. Tastet L, Capoulade R, Clavel M-A, Larose É, Shen M, Dahou A et al. Systolic hypertension and progression of aortic valve calcification in patients with aortic stenosis: results from the PROGRESSA study. European Heart Journal - Cardiovascular Imaging. 2017;18(1):70-8. DOI: 10.1093/ehjci/jew013

54. Liakos CI, Grassos CA, Papadopoulos DP, Dimitriadis KS, Tsioufis CP, Tousoulis D. Arterial hypertension and aortic valve stenosis: Shedding light on a common "liaison". Hellenic Journal of Cardiology. 2017;58(4):261-6. DOI: 10.1016/j.hjc.2017.03.005

55. Dweck MR, Boon NA, Newby DE. Calcific Aortic Stenosis: a disease of the valve and the myocardium. Journal of the American College of Cardiology. 2012;60(19):1854-63. DOI: 10.1016/j. jacc.2012.02.093

56. Rattazzi M, Bertacco E, Del Vecchio A, Puato M, Faggin E, Pauletto P. Aortic valve calcification in chronic kidney disease. Nephrology Dialysis Transplantation. 2013;28(12):2968-76. DOI: $10.1093 / \mathrm{ndt} /$ gft310

57. Ahmad S, Varagic J, VonCannon JL, Groban L, Collawn JF, Dell'Italia LJ et al. Primacy of cardiac chymase over angiotensin converting enzyme 
as an angiotensin-(1-12) metabolizing enzyme. Biochemical and Biophysical Research Communications. 2016;478(2):559-64. DOI: 10.1016/j.bbrc.2016.07.100

58. Nagata S, Hatakeyama K, Asami M, Tokashiki M, Hibino H, Nishiuchi $\mathrm{Y}$ et al. Big angiotensin-25: A novel glycosylated angiotensin-related peptide isolated from human urine. Biochemical and Biophysical Research Communications. 2013;441(4):757-62. DOI: 10.1016/j.bbrc.2013.10.124

59. Nagata S, Kato J, Sasaki K, Minamino N, Eto T, Kitamura K. Isolation and identification of proangiotensin-12, a possible component of the renin-angiotensin system. Biochemical and Biophysical Research Communications. 2006;350(4):1026-31. DOI: 10.1016/j. bbrc.2006.09.146

60. Ahmad S, Simmons T, Varagic J, Moniwa N, Chappell MC, Ferrario CM. Chymase-Dependent Generation of Angiotensin II from Angiotensin-(1-12) in Human Atrial Tissue. PLoS ONE. 2011;6(12):e28501. DOI: 10.1371/journal.pone.0028501

61. Ahmad S, Wei C-C, Tallaj J, Dell'Italia LJ, Moniwa N, Varagic J et al. Chymase mediates angiotensin-(1-12) metabolism in normal human hearts. Journal of the American Society of Hypertension. 2013;7(2):128-36. DOI: 10.1016/j.jash.2012.12.003

62. Helske S, Syväranta S, Kupari M, Lappalainen J, Laine M, Lommi J et al. Possible role for mast cell-derived cathepsin $G$ in the adverse remodelling of stenotic aortic valves. European Heart Journal. 2006;27(12):1495-504. DOI: 10.1093/eurheartj/ehi706

63. Coté N, Mahmut A, Bosse Y, Couture C, Pagé S, Trahan S et al. Inflammation Is Associated with the Remodeling of Calcific Aortic Valve Disease. Inflammation. 2013;36(3):573-81. DOI: 10.1007/ s10753-012-9579-6

64. Šteiner I, Krbal L, Rozkoš T, Harrer J, Laco J. Calcific aortic valve stenosis: Immunohistochemical analysis of inflammatory infiltrate. Pathology - Research and Practice. 2012;208(4):231-4. DOI: 10.1016/j.prp.2012.02.009

65. Šteiner I, Stejskal V, Žáček P. Mast cells in calcific aortic stenosis. Pathology - Research and Practice. 2018;214(1):163-8. DOI: 10.1016/j.prp.2017.07.016

66. O’Brien KD, Reichenbach DD, Marcovina SM, Kuusisto J, Alpers CE, Otto CM. Apolipoproteins B, (a), and E accumulate in the morphologically early lesion of 'degenerative' valvular aortic stenosis. Arteriosclerosis, Thrombosis, and Vascular Biology. 1996;16(4):52332. DOI: 10.1161/01.atv.16.4.523

67. Olsson M, Thyberg J, Nilsson J. Presence of oxidized low density lipoprotein in nonrheumatic stenotic aortic valves. Arteriosclerosis, Thrombosis, and Vascular Biology. 1999;19(5):1218-22. DOI: 10.1161/01.atv.19.5.1218

68. Parisi V, Leosco D, Ferro G, Bevilacqua A, Pagano G, de Lucia C et al. The lipid theory in the pathogenesis of calcific aortic stenosis. Nutrition, Metabolism and Cardiovascular Diseases. 2015;25(6):519-25. DOI: 10.1016/j.numecd.2015.02.001

69. Mohty D, Pibarot P, Després J-P, Côté C, Arsenault B, Cartier A et al. Association Between Plasma LDL Particle Size, Valvular Accumulation of Oxidized LDL, and Inflammation in Patients with Aortic Stenosis. Arteriosclerosis, Thrombosis, and Vascular Biology. 2008;28(1):18793. DOI: 10.1161/ATVBAHA.107.154989

70. Tiede K, Stöter K, Petrik C, Chen WB, Ungefroren $\mathrm{H}$, Kruse ML et al. Angiotensin II AT(1)-receptor induces biglycan in neonatal cardiac fibroblasts via autocrine release of TGFbeta in vitro. Cardiovascular Research. 2003;60(3):538-46.DOI: 10.1016/j.cardiores.2003.08.009

71. Neufeld EB, Zadrozny LM, Phillips D, Aponte A, Yu Z-X, Balaban RS. Decorin and biglycan retain LDL in disease-prone valvular and aortic subendothelial intimal matrix. Atherosclerosis. 2014;233(1):113-21. DOI: 10.1016/j.atherosclerosis.2013.12.038

72. Osman N, Grande-Allen KJ, Ballinger ML, Getachew R, Marasco S, O'Brien KD et al. Smad2-dependent glycosaminoglycan elongation in aortic valve interstitial cells enhances binding of LDL to proteoglycans. Cardiovascular Pathology. 2013;22(2):146-55. DOI: 10.1016/j.carpath.2012.07.002

73. Donoghue M, Hsieh F, Baronas E, Godbout K, Gosselin M, Stagliano N et al. A novel angiotensin-converting enzyme-related carboxypepti- dase (ACE2) converts angiotensin I to angiotensin 1-9. Circulation Research. 2000;87(5):E1-9. DOI: 10.1161/01.res.87.5.e1

74. Ferreira AJ, Santos RAS, Bradford CN, Mecca AP, Sumners C, Katovich MJ et al. Therapeutic Implications of the Vasoprotective Axis of the Renin-Angiotensin System in Cardiovascular Diseases. Hypertension. 2010;55(2):207-13. DOI: 10.1161/ HYPERTENSIONAHA.109.140145

75. Iwai M, Horiuchi M. Devil and angel in the renin-angiotensin system: ACE-angiotensin II-AT1 receptor axis vs. ACE2-angiotensin-(1-7)Mas receptor axis. Hypertension Research. 2009;32(7):533-6. DOI: 10.1038/hr.2009.74

76. Alenina N, Xu P, Rentzsch B, Patkin EL, Bader M. Genetically altered animal models for Mas and angiotensin-(1-7): Transgenic animal models for Mas and angiotensin-(1-7). Experimental Physiology. 2008;93(5):528-37. DOI: 10.1113/expphysiol.2007.040345

77. Kassiri Z, Zhong J, Guo D, Basu R, Wang X, Liu PP et al. Loss of Angiotensin-Converting Enzyme 2 Accelerates Maladaptive Left Ventricular Remodeling in Response to Myocardial Infarction. Circulation: Heart Failure. 2009;2(5):446-55. DOI: 10.1161/ CIRCHEARTFAILURE.108.840124

78. Zhong J, Basu R, Guo D, Chow FL, Byrns S, Schuster M et al. Angiotensin-Converting Enzyme 2 Suppresses Pathological Hypertrophy, Myocardial Fibrosis, and Cardiac Dysfunction. Circulation. 2010;122(7):717-28. DOI: 10.1161/ CIRCULATIONAHA.110.955369

79. Trask AJ, Groban L, Westwood BM, Varagic J, Ganten D, Gallagher PE et al. Inhibition of Angiotensin-Converting Enzyme 2 Exacerbates Cardiac Hypertrophy and Fibrosis in Ren-2 Hypertensive Rats. American Journal of Hypertension. 2010;23(6):687-93. DOI: 10.1038/ajh.2010.51

80. Peltonen T, Näpänkangas J, Ohtonen $\mathrm{P}$, Aro J, Peltonen J, Soini Y et al. (Pro)renin receptors and angiotensin converting enzyme 2/ angiotensin-(1-7)/Mas receptor axis in human aortic valve stenosis. Atherosclerosis. 2011;216(1):35-43. DOI: 10.1016/j.atherosclerosis.2011.01.018

81. Collister JP, Nahey DB. Simultaneous administration of Ang(1-7) or A-779 does not affect the chronic hypertensive effects of angiotensin II in normal rats. Journal of the Renin-Angiotensin-Aldosterone System. 2010;11(2):99-102. DOI: 10.1177/1470320309359928

82. Velkoska E, Dean RG, Griggs K, Burchill L, Burrell LM. Angiotensin-(1-7) infusion is associated with increased blood pressure and adverse cardiac remodelling in rats with subtotal nephrectomy. Clinical Science. 2011;120(8):335-45. DOI: 10.1042/CS20100280

83. Shao Y, He M, Zhou L, Yao T, Huang Y, Lu L. Chronic angiotensin (17) injection accelerates STZ-induced diabetic renal injury 1 . Acta Pharmacologica Sinica. 2008;29(7):829-37. DOI: 10.1111/j.17457254.2008.00812.x

84. Mendoza-Torres E, Oyarzún A, Mondaca-Ruff D, Azocar A, Castro PF, Jalil JE et al. ACE2 and vasoactive peptides: novel players in cardiovascular/renal remodeling and hypertension. Therapeutic Advances in Cardiovascular Disease. 2015;9(4):217-37. DOI: $10.1177 / 1753944715597623$

85. Westermeier F, Bustamante M, Pavez M, García L, Chiong M, Ocaranza MP etal.Novel players in cardioprotection: Insulin like growth factor-1, angiotensin-(1-7) and angiotensin-(1-9). Pharmacological Research. 2015;101:41-55. DOI: 10.1016/j.phrs.2015.06.018

86. Ocaranza MP, Lavandero S, Jalil JE, Moya J, Pinto M, Novoa U et al. Angiotensin-(1-9) regulates cardiac hypertrophy in vivo and in vitro. Journal of Hypertension. 2010;28(5):1054-64. DOI: 10.1097/ HJH.0b013e328335d291

87. Ocaranza MP, Moya J, Barrientos V, Alzamora R, Hevia D, Morales C et al. Angiotensin-(1-9) reverses experimental hypertension and cardiovascular damage by inhibition of the angiotensin converting enzyme/Ang II axis: Journal of Hypertension. 2014;32(4):771-83. DOI: $10.1097 / \mathrm{HJH} .0000000000000094$

88. Zheng H, Pu S-Y, Fan X-F, Li X-S, Zhang Y, Yuan J et al. Treatment with angiotensin-(1-9) alleviates the cardiomyopathy in streptozotocin-induced diabetic rats. Biochemical Pharmacology. 2015;95(1):3845. DOI: $10.1016 /$ j.bcp.2015.03.009 
89. Cha SAh, Park BM, Gao S, Kim SH. Stimulation of ANP by angiotensin-(1-9) via the angiotensin type 2 receptor. Life Sciences. 2013;93(24):934-40. DOI: 10.1016/j.lfs.2013.10.020

90. Flores-Munoz M, Work LM, Douglas K, Denby L, Dominiczak AF, Graham D et al. Angiotensin-(1-9) Attenuates Cardiac Fibrosis in the Stroke-Prone Spontaneously Hypertensive Rat via the Angiotensin Type 2 Receptor. Hypertension. 2012;59(2):300-7. DOI: 10.1161/ HYPERTENSIONAHA.111.177485

91. Yu L, Yuan K, Phuong HTA, Park BM, Kim SH. Angiotensin-(1-5), an active mediator of renin-angiotensin system, stimulates ANP secretion via Mas receptor. Peptides. 2016;86:33-41. DOI: 10.1016/j.peptides.2016.09.009

92. Hrenak J, Paulis L, Simko F. Angiotensin A/Alamandine/MrgD Axis: Another Clue to Understanding Cardiovascular Pathophysiology. International Journal of Molecular Sciences. 2016;17(7):1098. DOI: 10.3390/ijms 17071098

93. Lautner RQ, Villela DC, Fraga-Silva RA, Silva N, Verano-Braga T, CostaFraga F et al. Discovery and Characterization of Alamandine: A Novel Component of the Renin-Angiotensin System. Circulation Research. 2013;112(8):1104-11. DOI: 10.1161/CIRCRESAHA.113.301077

94. Villela DC, Passos-Silva DG, Santos RAS. Alamandine: a new member of the angiotensin family. Current Opinion in Nephrology and Hypertension. 2014;23(2):130-4. DOI: 10.1097/01. mnh.0000441052.44406.92

95. Habiyakare B, Alsaadon H, Mathai ML, Hayes A, Zulli A. Reduction of angiotensin A and alamandine vasoactivity in the rabbit model of atherogenesis: differential effects of alamandine and $\operatorname{Ang}(1-7)$. International Journal of Experimental Pathology. 2014;95(4):290-5. DOI: 10.1111 iep.12087

96. Jankowski V, Tölle M, Santos RAS, GünthnerT, Krause E, Beyermann M et al. Angioprotectin: an angiotensin II-like peptide causing vasodilatory effects. The FASEB Journal. 2011;25(9):2987-95. DOI: 10.1096/ fi.11-185470

97. Jankowski V, Vanholder R, van der Giet M, Tölle M, Karadogan S, Gobom J et al. Mass-Spectrometric Identification of a Novel Angiotensin Peptide in Human Plasma. Arteriosclerosis, Thrombosis, and Vascular Biology. 2007;27(2):297-302. DOI: 10.1161/01. ATV.0000253889.09765.5f

98. Yang R, Smolders I, Vanderheyden P, Demaegdt H, Van Eeckhaut A, Vauquelin $G$ et al. Pressor and Renal Hemodynamic Effects of the Novel Angiotensin A Peptide Are Angiotensin II Type 1A Receptor Dependent. Hypertension. 2011;57(5):956-64. DOI: 10.1161/ HYPERTENSIONAHA.110.161836

99. Coutinho DC, Foureaux G, Rodrigues KD, Salles RL, Moraes PL, Murça TM et al. Cardiovascular effects of angiotensin A: A novel peptide of the renin-angiotensin system. Journal of the ReninAngiotensin-Aldosterone System. 2014;15(4):480-6. DOI: $10.1177 / 1470320312474856$

100. Ngo DT, Stafford I, Sverdlov AL, Qi W, Wuttke RD, Zhang Y et al. Ramipril retards development of aortic valve stenosis in a rabbit model: mechanistic considerations: Ramipril retards development of aortic valve stenosis. British Journal of Pharmacology. 2011;162(3):722-32. DOI: 10.1111/j.1476-5381.2010.01084.x

101. Simolin MA, Pedersen TX, Bro S, Mäyränpää MI, Helske S, Nielsen LB et al. ACE inhibition attenuates uremia-induced aortic valve thickening in a novel mouse model. BMC Cardiovascular Disorders. 2009;9(1):10. DOI: $10.1186 / 1471-2261-9-10$

102. Bull S, Loudon M, Francis JM, Joseph J, Gerry S, Karamitsos TD et al. A prospective, double-blind, randomized controlled trial of the angiotensin-converting enzyme inhibitor Ramipril In Aortic Stenosis (RIAS trial). European Heart Journal - Cardiovascular Imaging. 2015;16(8):834-41. DOI: $10.1093 /$ ehjci/jev043

103. Chockalingam A, Venkatesan S, Subramaniam T, Jagannathan V, Elangovan $S$, Alagesan $R$ et al. Safety and efficacy of angiotensin-converting enzyme inhibitors in symptomatic severe aortic stenosis: symptomatic cardiac obstruction-pilot study of enalapril in aortic stenosis
(SCOPE-AS). American Heart Journal. 2004;147(4):740. DOI: 10.1016/j. ahj.2003.10.017

104. Dalsgaard M, Iversen K, Kjaergaard J, Grande P, Goetze JP, Clemmensen P et al. Short-term hemodynamic effect of angiotensin-converting enzyme inhibition in patients with severe aortic stenosis. American Heart Journal. 2014;167(2):226-34. DOI: 10.1016/j.ahj.2013.11.002

105. Capoulade R, Clavel M-A, Mathieu P, Côté N, Dumesnil JG, Arsenault $\mathrm{M}$ et al. Impact of hypertension and renin-angiotensin system inhibitors in aortic stenosis. European Journal of Clinical Investigation. 2013;43(12):1262-72. DOI: 10.1111/eci.12169

106. Côté N, Couture C, Pibarot P, Després J-P, Mathieu P. Angiotensin receptor blockers are associated with a lower remodelling score of stenotic aortic valves. European Journal of Clinical Investigation. 2011;41(11):1172-9. DOI: $10.1111 /$ j.1365-2362.2011.02522.x

107. Yamamoto K, Yamamoto H, Yoshida K, Kisanuki A, Hirano Y, Ohte N et al. Prognostic factors for progression of early- and late-stage calcific aortic valve disease in Japanese: The Japanese Aortic Stenosis Study (JASS) Retrospective Analysis. Hypertension Research. 2010;33(3):269-74. DOI: $10.1038 / \mathrm{hr} .2009 .225$

108. Rosenhek R, Rader F, Loho N, Gabriel H, Heger M, Klaar U et al. Statins but Not Angiotensin-Converting Enzyme Inhibitors Delay Progression of Aortic Stenosis. Circulation. 2004;110(10):1291-5. DOI: 10.1161/01. CIR.0000140723.15274.53

109. O’Brien KD, Probstfield JL, Caulfield MT, Nasir K, Takasu J, Shavelle DM et al. Angiotensin-Converting Enzyme Inhibitors and Change in Aortic Valve Calcium. Archives of Internal Medicine. 2005;165(8):858-62. DOI: 10.1001/archinte.165.8.858

110. Nadir MA, Wei L, Elder DHJ, Libianto R, Lim TK, Pauriah M et al. Impact of Renin-Angiotensin System Blockade Therapy on Outcome in Aortic Stenosis. Journal of the American College of Cardiology. 2011;58(6):5706. DOI: $10.1016 /$ j.jacc.2011.01.063

111. Chen J-H, Simmons CA. Cell-Matrix Interactions in the Pathobiology of Calcific Aortic Valve Disease: Critical Roles for Matricellular, Matricrine, and Matrix Mechanics Cues. Circulation Research. 2011;108(12):151024. DOI: 10.1161 /CIRCRESAHA.110.234237

112. Yip CYY, Simmons CA. The aortic valve microenvironment and its role in calcific aortic valve disease. Cardiovascular Pathology. 2011;20(3):17782. DOI: $10.1016 /$ j.carpath.2010.12.001

113. Balachandran K, Sucosky P, Jo H, Yoganathan AP. Elevated Cyclic Stretch Induces Aortic Valve Calcification in a Bone Morphogenic ProteinDependent Manner. The American Journal of Pathology. 2010;177(1):4957. DOI: 10.2353 /ajpath.2010.090631

114. Helske-Suihko S, Laine M, Lommi J, Kaartinen M, Werkkala K Kovanen PT et al. Is Blockade of the Renin-angiotensin System Able to Reverse the Structural and Functional Remodeling of the Left Ventricle in Severe Aortic Stenosis? Journal of Cardiovascular Pharmacology. 2015;65(3):233-40. DOI: 10.1097/FJC.0000000000000182

115. Bang CN, Greve AM, Køber L, Rossebø AB, Ray S, Boman K et al. Reninangiotensin system inhibition is not associated with increased sudden cardiac death, cardiovascular mortality or all-cause mortality in patients with aortic stenosis. International Journal of Cardiology. 2014;175(3):492-8. DOI: 10.1016/j.ijcard.2014.06.013

116. Dell'Italia LJ, Collawn JF, Ferrario CM. Multifunctional Role of Chymase in Acute and Chronic Tissue Injury and Remodeling. Circulation Research. 2018;122(2):319-36. DOI: 10.1161/CIRCRESAHA.117.310978

117. Ahmad S, Ferrario CM. Chymase inhibitors for the treatment of cardiac diseases: a patent review (2010-2018). Expert Opinion on Therapeutic Patents. 2018;28(11):755-64. DOI: 10.1080/13543776.2018.1531848

118. Nguyen G, Muller DN. The Biology of the (Pro)Renin Receptor. Journal of the American Society of Nephrology. 2010;21(1):18-23. DOI: 10.1681/ASN.2009030300

119. Cruciat C-M, Ohkawara B, Acebron SP, Karaulanov E, Reinhard C, Ingelfinger $\mathrm{D}$ et al. Requirement of Prorenin Receptor and Vacuolar H+-ATPase-Mediated Acidification for Wnt Signaling. Science. 2010;327(5964):459-63. DOI: 10.1126/science.1179802

Статья поступима 03.12.18 (Received 03.12.18) 